\title{
Vasotocin actions on electric behavior: interspecific, seasonal, and social context-dependent differences
}

\author{
Rossana Perrone ${ }^{1,2}$, Gervasio Batista ${ }^{1,2}$, Daniel Lorenzo', Omar Macadar' and Ana Silva ${ }^{2,3 *}$ \\ - Departamento de Neurofisiología, Instituto Clemente Estable, Ministerio de Educación y Cultura, Montevideo, Uruguay \\ 2 Unidad Bases Neurales de la Conducta, Instituto Clemente Estable, Ministerio de Educación y Cultura, Montevideo, Uruguay \\ ${ }^{3}$ Laboratorio de Neurociencias, Facultad de Ciencias, Universidad de la República, Montevideo, Uruguay
}

Edited by:

Kathleen A. French, University of

California San Diego, USA

Reviewed by:

Andrew Bass, Cornell University, USA

Kathleen A. French, University of

California San Diego, USA

*Correspondence:

Ana Silva, Faculdad de Ciencias-

Instituto de Investigaciones Biológicas Clemente Estable, Unidad Bases

Neurales de la Conducta, Avda Italia 3318, 11600 Montevideo, Uruguay.

e-mail:asilva@iibce.edu.uy
Social behavior diversity is correlated with distinctively distributed patterns of a conserved brain network, which depend on the action of neuroendocrine messengers that integrate extrinsic and intrinsic cues. Arginine vasotocin (AVT) is a key integrator underlying differences in behavior across vertebrate taxa. Weakly electric fish use their electric organ discharges (EODs) as social behavioral displays. We examined the effect of AVT on EOD rate in two species of Gymnotiformes with different social strategies: Gymnotus omarorum, territorial and highly aggressive, and Brachyhypopomus gauderio, gregarious and aggressive only between breeding males. AVT induced a long-lasting and progressive increase of EOD rate in isolated $B$. gauderio, partially blocked by the V1a AVT receptor antagonist (Manning compound, $\mathrm{MC}$ ), and had no effects in G. omarorum. AVT also induced a long-lasting increase in the firing rate (prevented by $\mathrm{MC}$ ) of the isolated medullary pacemaker nucleus (PN) of $B$. gauderio when tested in an in vitro preparation, indicating that the PN is the direct effector of AVT actions. AVT is involved in the seasonal, social context-dependent nocturnal increase of EOD rate that has been recently described in B. gauderio to play a role in mate selection. AVT produced the additional nocturnal increase of EOD rate in non-breeding males, whereas $\mathrm{MC}$ blocked it in breeding males. Also, AVT induced a larger EOD rate increase in reproductive dyads than in agonistic encounters. We demonstrated interspecific, seasonal, and context-dependent actions of AVT on the PN that contribute to the understanding of the mechanisms the brain uses to shape sociality.

Keywords: AVT, electric fish, Brachyhypopomus gauderio, Gymnotus omarorum, pacemaker nucleus, EOD rate, social behavior

\section{INTRODUCTION}

The extraordinary diversity and complexity of social behavior have made it difficult to attain a comprehensive knowledge of their underlying neural mechanisms. Among vertebrates, behaviors such as affiliation, reproduction and aggression are regulated by the same highly conserved network in the limbic forebrain and midbrain (or their equivalent in non-tetrapod taxa) (Newman, 1999; Goodson, 2005; Goodson and Kabelik, 2009). Variation in activity of this network would therefore generate the variations of social behavior among species, individuals within a population, and ontogenic stages within an individual. It has been recently postulated that inter and intraspecific modulations of behavior are correlated with distinctively distributed patterns of this network, and that these modulations depend on the action of neuroendocrine messengers that integrate extrinsic and intrinsic cues (Goodson and Kabelik, 2009). Even though behavioral neuroscience cannot usually explore distributed functional patterns directly, several studies have revealed molecular, cellular, and circuital mechanisms of social behavior (Young, 2009).

The hypothalamic neuropeptide arginine vasotocin (AVT) and its mammalian homologue, vasopressin, are key integrators underlying interspecific, sexual, individual, and social context differences in behavior in vertebrates (Insel and Young, 2000; Goodson and Bass, 2001; Goodson, 2008). Although the structure of the peptide AVT and its receptor (V1a) are highly conserved across taxa, AVT modulates social behavior in a species-specific manner. In many vertebrates, it induces species-specific sexually dimorphic responses to seasonal and daily changes in the environment (Goodson and Bass, 2001; De Vries and Panzica, 2006; Goodson, 2008). Comparative studies of AVT actions between related species with different social structure, for example in voles (Young et al., 1997), songbirds (Goodson, 1998a,b), and fish (Dewan et al., 2008) have been especially valuable in the understanding of the evolution of neural mechanisms regulating social behavior. However, behavioral approaches cannot always reveal the bases of this neuromodulation unambiguously. Recent studies have demonstrated a fine tuning of AVT modulation of aggression in birds that varies across contexts and phenotypes (Goodson and Kabelik, 2009). It is therefore necessary to design rigorous behavioral experiments in advantageous model systems, in which we can use a neuroethological approach that incorporates the life history of the individual and the ecology of the species into studies of its behavior and neural regulation.

As a classic neuroethological model, electric fish display easily measurable, conspicuous, and distinctive social behaviors that depend on a well-described neural circuit. South American electric fish (Order Gymnotiformes) are nocturnal and use their electric signals to communicate among conspecifics (Lissmann, 1958). 
The electric organ discharge (EOD) carries information about an individual's species identity, sex, and physiological state, which is coded both by the discharge rate and waveform of the EOD (Caputi et al., 2005). EOD rate is controlled by a single medullary pacemaker nucleus (PN), which is composed of intrinsically firing electrotonically coupled pacemaker cells that drive larger bulbospinal relay cells (Caputi et al., 2005). The PN fires at a regular basal rhythm, but also responds to changes in the environment, hormonal state, and social context (Stoddard, 2002). In some gymnotiforms, EOD rate varies by season, time of day, temperature, sex, social status, locomotor activity, and presence of novel stimuli (Silva et al., 2007). In addition to making these changes in basal rate of the EOD, the fish also make rapid modulations of the EOD to produce transient communication signals (e.g., chirps, accelerations, and interruptions) that are displayed in different behavioral scenarios (Lorenzo et al., 2006). These modulations result from the activity of separate higher centers, pre-pacemaker nuclei, which briefly change the firing rate of the PN (Kawasaki and Heiligenberg, 1989, 1990; Keller et al., 1991).

In this study, our first goal was to demonstrate interspecific differences in the effect of AVT on electric behavior in two sympatric pulse-type weakly electric fish that exhibit different social strategies. Gymnotus omarorum (Richer-de-Forges et al., 2009), is territorial and highly aggressive regardless of sex and season, and Brachyhypopomus gauderio (Giora and Malabarba, 2009), is gregarious and aggression is displayed only between males during the breeding season. We examined the effect of AVT on a very simple and comparable electric display: the EOD basal rate of isolated fish during daytime. Our results show interspecific differences in this clearly homologous behavior, which can only be interpreted as a differential organization of the AVTergic system (projections and/ or receptors) at the level of the $\mathrm{PN}$.

Pulse electric fish enhance their EOD rate during the nighttime when they are active (Black-Cleworth, 1970; Kawasaki and Heiligenberg, 1989). Our group has recently found that B. gauderio displays an additional previously undescribed nocturnal increase of EOD rate (Silva et al., 2007). This electric display occurs in malefemale dyads but not in isolated fish, and only during breeding season (Silva et al., 2007). In the second part of this study we demonstrated the involvement of AVT in this additional increase of nocturnal EOD rate, a behavior that seems key for mate choice and courtship, in males of B. gauderio.

\section{MATERIALS AND METHODS FISH COLLECTION AND HOUSING}

We used males of Brachyhypopomus gauderio (Giora and Malabarba, 2009), formerly B. pinnicaudatus (Hopkins, 1991), and adults of Gymnotus omarorum, formerly G. carapo, (Richer-de-Forges et al., 2009). B. gauderio exhibits an obvious morphological sexual dimorphism (Hopkins, 1991) that allowed us to easily distinguish males from females. Sex in G. omarorum is not externally apparent and was determined after the behavioral experiments by gonadal inspection.

Fish were detected and collected at three lakes in Uruguay using a "fish detector", an electronic audio amplifier connected to a pair of electrodes, as described elsewhere (Silva et al., 2003). Fish were collected during the breeding seasons of 2007-2009 (that occur during the Austral summer, November-January (Silva et al., 2003), and during the non-breeding seasons of 2008-2009 (May-July). B. gauderio were collected from Laguna El Tigre $\left(33^{\circ} 18^{\prime} \mathrm{S}, 54^{\circ} 35^{\prime} \mathrm{W}\right.$, Department of Treinta y Tres) and Laguna Lavalle $\left(31^{\circ} 48^{\prime} \mathrm{S}, 55^{\circ} 13^{\prime} \mathrm{W}\right.$, Department of Tacuarembó), and G. omarorum were collected from Laguna del Sauce $\left(34^{\circ} 51^{\prime} \mathrm{S}, 55^{\circ} 07^{\prime} \mathrm{W}\right.$, Department of Maldonado). To achieve reliable and repeatable behaviors, our collection, transportation, housing, and recording conditions were adjusted to minimize stress on the animals. Fish showed no signs of distress throughout the experiments. All experiments were performed in accordance with institutional and national guidelines and regulations for animal welfare (Comisión Honoraria Experimentación Animal, Universidad de la República).

In accordance with their different social structure, B. gauderio were housed in 500-l outdoor tanks in social groups of two males and six females. This group composition replicates the sex ratio in breeding colonies in their natural habitat (Miranda et al., 2008). G. omarorum were housed in individual compartments within 500-1 outdoor tanks. Water temperature in the tanks ranged from 8 to $33^{\circ} \mathrm{C}$ throughout the year, which is within the normal range of the natural habitat (Silva et al., 2003). Extreme temperatures outside this range were avoided by covering the tanks with plastic in winter and by shading them during the summer. Natural photoperiod ranged seasonally from LD10:14 in winter to LD14:10 in summer. Water conductivity was adjusted and maintained below $150 \mu \mathrm{S} / \mathrm{cm}$ by the addition of deionized water. Aquatic plants (Eichhornia crassipes, Pistia stratiotes, Salvinia sp.) covered the surface of the water and provided shelter for the fish. Fish were fed Tubifex tubifex.

\section{BEHAVIORAL EXPERIMENTS}

Fish were placed in an experimental setup that allowed simultaneous video and electric recordings as described elsewhere (Silva et al., 2007; Perrone et al., 2009). The experimental tanks, four 40-1 glass aquaria $(55 \mathrm{~cm} \times 40 \mathrm{~cm} \times 25 \mathrm{~cm})$ were fitted with two pairs of orthogonal electrodes attached to each tank wall. The day-night cycle and the physicochemical parameters (water temperature, conductivity, and $\mathrm{pH}$ ) of the outdoor housing tanks were reproduced in the indoor aquaria. The fish remained in the recording tank at constant temperature $\left(20-22^{\circ} \mathrm{C}\right.$ in the non-breeding season; $27-29^{\circ} \mathrm{C}$ in the breeding season) for $12 \mathrm{~h}$ before the beginning of the experiment. Daytime experiments were done under white light illumination, and night experiments were performed in total darkness illuminated by an array of infrared LEDs (L-53F3BT, Fablet and Bertoni Electronics) located above the tank. An infrared-sensitive video camera (SONY CCD-Iris) was focused upon the bottom of the tank. The EODs of freely moving fish were detected by two pairs of fixed electrodes, connected to two high-input impedance amplifiers (FLA-01, Cygnus Technologies Inc.). Images and electric signals were captured by a video card (Pinnacle Systems, PCTV-HD pro stick) and stored in the computer. Images were further analyzed with software developed in the laboratory.

The effect of AVT (IP, 1-10 $\mu \mathrm{g} / \mathrm{gbw}$ ) (Lema and Nevitt, 2004; Santangelo and Bass, 2006) on EOD rate was tested against saline controls in isolated freely-swimming fish of B. gauderio) and G. omarorum $(10 \mu \mathrm{g} / \mathrm{gbw})$ during daytime $(10-13 \mathrm{~h})$ in both the nonbreeding season ( $n=6$ per treatment group, B. gauderio: $n=24, G$. omarorum: $n=12)$ and breeding season ( $n=6$ per treatment group, 
B. gauderio: $n=12, G$. omarorum: $n=12$ ). We used only males of B. gauderio. In G. omarorum, we used adults of both sexes whose data were pooled. We tested locomotor activity $1 \mathrm{~h}$ before and 60-120 min after AVT administration by measuring the frequency of two behavioral states (motion and motionless) in 1 min samples taken each $5 \mathrm{~min}$. To test the specificity of AVT action, the V1a AVT receptor antagonist (Manning compound, MC, IP, 1.5-10 $\mu \mathrm{g} / \mathrm{gbw}$ ) was administered $5 \mathrm{~min}$ before AVT (IP, $1 \mu \mathrm{g} / \mathrm{gbw}$ ) in B. gauderio $(n=6)$. Following Santangelo and Bass (2006), we first tried the lowest MC dose reported for IP experiments in teleosts $(1.5 \mu \mathrm{g} /$ gbw), which was also effective in antagonizing AVT effects in $B$. gauderio (data not shown). To enable comparisons across seasons and species, we used a higher dose that evoked similar effects and was well-tolerated by fish $(10 \mu \mathrm{g} / \mathrm{gbw})$. We tested the effects of MC for $120 \mathrm{~min}$ after its administration as in previous studies in teleosts (Lema and Nevitt, 2004; Santangelo and Bass, 2006). We explored the effect of endogenous AVT on the EOD diurnal rate of G. omarorum by administering $\mathrm{MC}(10 \mu \mathrm{g} / \mathrm{gbw})$ to non-breeding isolated individuals $(n=6)$. During the breeding season, we tested the effect of the $\mathrm{MC}$ on the characteristic additional nocturnal increase of EOD rate previously reported by our group (Silva et al., 2007) in male-female dyads $(n=6)$ of B. gauderio using a 2-day protocol (Protocol I). The effect of AVT on the nocturnal increase of EOD rate (Silva et al., 2007) was tested in male-female dyads $(n=6)$ of B. gauderio during the breeding and non-breeding seasons using a 3-day protocol (Protocol II). We also tested male-male dyads $(n=6)$ of B. gauderio during the breeding season using a 3-day protocol (Protocol II). Dyads were always recorded $1 \mathrm{~h}$ before and $2 \mathrm{~h}$ after the artificial sunset. In Protocol I we recorded the electric displays of a male-female dyad on day 1 to assess whether the male increased its EOD rate at least 50\% and emitted social electric signals (Silva et al., 2007; Perrone et al., 2009). If so, Protocol I continued to day 2 in which the MC (IP, $10 \mu \mathrm{g} / \mathrm{gbw}$ ) was administered to the male 15 min prior to the artificial sunset. In Protocol II: the males were screened on day 1 for nocturnal rate increases and social electric signals as in Protocol I. On day 2, the male was injected with saline (IP, $100 \mu \mathrm{l}$ ) $5 \mathrm{~min}$ prior to the beginning of the recordings, and on day 3 with AVT (IP, $10 \mu \mathrm{g} / \mathrm{gbw}, 100 \mu \mathrm{l}$ ). For male-male dyads, the female was replaced by 2 different intruder males on days 2 and 3, respectively. For comparative purposes, Protocol II was also used during the non-breeding season although the additional increase of nocturnal EOD rate was obviously not observed during the night of day 1 (Silva et al., 2007).

\section{IN VITRO EXPERIMENTS}

Brachyhypopomus gauderio $(n=10)$ were anesthetized with pentobarbital sodium (Merck, IP, $25 \mu \mathrm{g} / \mathrm{gbw}$ ) since regular fish anesthetics such as MS222 (Falconi et al., 1997) and phenoxyethanol (unpublished observations) interfered with the activity of the PN and were therefore avoided. The dorsal surface of the brain was exposed while bathed with cold sodium-free Ringer-sucrose solution (containing in mM 209 sucrose, $3 \mathrm{KCl}, 0.75 \mathrm{KH}_{2} \mathrm{PO}_{4}, 1.2 \mathrm{MgSO}_{4}, 1.6 \mathrm{CaCl}_{2}, 24$ $\mathrm{NaHCO}_{3}$, and 10 D-glucose, $\mathrm{pH}=7.4$ after saturation with $95 \%$ $\mathrm{O}_{2}-5 \% \mathrm{CO}_{2}$ ). The brain with part of the spinal cord was rapidly removed from the skull and submerged in cold Ringer-sucrose solution. The entire surgical procedure took less than $5 \mathrm{~min}$. Transverse sections of the brain (500- $\mu \mathrm{m}$ thick) were obtained under cold
Ringer-sucrose using a motorized vibroslice (WPI, NVSLM1). Slices were incubated at room temperature for $30 \mathrm{~min}$ in a 1:1 solution of Ringer-sucrose and fish Ringer (containing in $\mathrm{mM} 124$ $\mathrm{NaCl}, 3 \mathrm{KCl}, 0.75 \mathrm{KH}_{2} \mathrm{PO}_{4}, 1.2 \mathrm{MgSO}_{4}, 1.6 \mathrm{CaCl}_{2}, 24 \mathrm{NaHCO}_{3}$, and 10 D-glucose, $\mathrm{pH}=7.4$ after saturation with $95 \% \mathrm{O}_{2}-5 \% \mathrm{CO}_{2}$ ). Slices were then transferred to the recording chamber containing fish Ringer solution. After visual observation with a dissecting microscope, only the slice containing the PN was maintained in the recording chamber and superfused with oxygenated Ringer solution at room temperature $\left(17-22^{\circ} \mathrm{C}\right)$. In these conditions, the PN maintains its spontaneous synchronized activity with a stable firing rate for several hours. All the experiments were carried out during daytime (10-16 h).

Field potential recordings of the PN activity were performed with low resistance glass micropipettes (3-5 M $\Omega$ ) filled with Ringer solution. The field potential reflects the activation of a population of pacemaker and relay cells in close proximity with the micropipette (Figure 6A). Signals were amplified (AM Systems, M3000, filters $150-3000 \mathrm{~Hz}$ ) and fed to a computer for further analysis. After recording basal activity for $30 \mathrm{~min}$, we tested the effect of AVT perfusion on the firing rate of the PN. AVT $(20 \mu \mathrm{l}$ of a solution of $1 \mu \mathrm{g} / \mu \mathrm{l}, n=6$ ) was added to an intermediate chamber and driven to the recording chamber by the flow of Ringer solution. The chamber volume and the amount of Ringer driving the AVT to the chamber were adjusted to obtain a final AVT concentration of $1 \mu \mathrm{M}$ (analogous to an intermediate dose of AVT of those used in behavioral experiments). The perfusion was then stopped for 30 min to maintain a constant AVT concentration in the chamber. Then, the washout with Ringer solution was initiated and maintained throughout the experiment. Control experiments have previously demonstrated that the spontaneous PN firing rate is affected by neither the termination nor the onset of perfusion. We tested the effect of MC in four experiments, adding it to the intermediate chamber $(60 \mu \mathrm{l}$ of a solution of $1 \mu \mathrm{g} / \mu \mathrm{l}$, resulting in a final concentration of $10 \mu \mathrm{M}, n=4$ ), followed by AVT administration (same dose) $30 \mathrm{~min}$ later.

\section{DATA PROCESSING AND STATISTICS}

We took 10-60 s-EOD recordings every $5 \mathrm{~min}$, and calculated the mean EOD interval in each sample using the software Clampfit (Axon, 10.0.0.61). This interval was converted to frequency and represented the EOD rate of each sample. The median EOD rate of $1 \mathrm{~h}$ of recordings was considered the representative EOD rate. For comparisons, the amplitude of the effect of IP treatments was quantified as the percentage of EOD rate increase (treatment index, TI) calculated as follows: the difference between the representative EOD rate of the time interval 60-120 min after treatment and the representative EOD rate of the time interval $1 \mathrm{~h}$ before treatment normalized to the representative EOD rate of the time interval $1 \mathrm{~h}$ before treatment. In some cases, the EOD rate increase was similarly calculated for partial time windows (time intervals 0-30 min, 90-120 min, Table 1, Figure 1D). To evaluate the timing of the AVT effect on EOD rate, we measured the time it took for the effect to reach $90 \%$ of its maximal value. To avoid the bias of the variability of the data, we fit our data to a sigmoidal curve $\left(R^{2}>0.8\right.$ in all cases) and measured the time at $90 \%$ of its upper asymptote (T90, Table 1, Figure 1C). Following Silva et al. 
Table 1 | Quantification of the effects of AVT upon EOD rate in Brachyhypopomus gauderio.

\begin{tabular}{|c|c|c|c|c|c|}
\hline Condition & Median & IQR & Test & $n$ & $p$ \\
\hline & $\mathrm{TI}(\%)$ & & & & \\
\hline & T90 (min) & & & & \\
\hline \multicolumn{6}{|l|}{ NON-BREEDING } \\
\hline TI AVT $1 \mu \mathrm{g} / \mathrm{gbw}$ & 57.72 & 31.7 & Mann-Whitney $U$ & 6 & 0.002 \\
\hline TI saline & -5.86 & 8.6 & & 6 & \\
\hline TI saline & -5.86 & 8.6 & Mann-Whitney $U$ & 6 & 0.001 \\
\hline 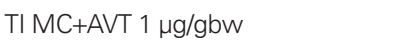 & 21.91 & 23.9 & & 6 & \\
\hline 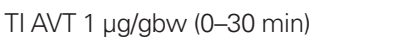 & 17.96 & 17.5 & Wilcoxon-Matched-Pairs & 6 & 0.03 \\
\hline TI AVT 1 нg/gbw (90-120 min) & 63.72 & 29.1 & & 6 & \\
\hline 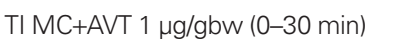 & 0.16 & 10.2 & Wilcoxon-Matched-Pairs & 6 & 0.018 \\
\hline 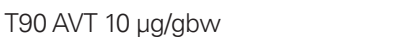 & 21.78 & 21.4 & & 6 & \\
\hline \multicolumn{6}{|l|}{ SEASONALITY (AVT $10 \mu \mathrm{G} / \mathrm{GBW}$ ) } \\
\hline TI non-breeding & 68.63 & 85.7 & Mann-Whitney $U$ & 6 & 0.09 \\
\hline TI breeding & 146.83 & 61.1 & & 6 & \\
\hline T90 non-breeding & 21.78 & 21.4 & Mann-Whitney $U$ & 6 & 1.06 \\
\hline T90 breeding & 15.59 & 15.2 & & 6 & \\
\hline
\end{tabular}

Statistics of the effects of AVT (amplitude of the increase of EOD rate and time course) vs saline controls, vs fish that received MC (10 $\mu g / g b w)+A V T$ (1 $\mu g / g b w)$,

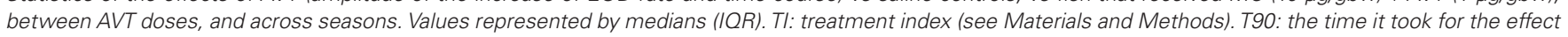

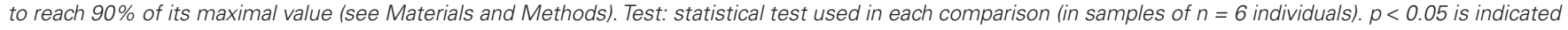
in bold letters.

(2007), the amplitude of the nocturnal increase of EOD rate was similarly calculated as the difference in percentage between the representative EOD rate of the time interval 60-120 min after sunset and the representative EOD rate of the time interval $1 \mathrm{~h}$ before sunset normalized to the representative EOD rate of the time interval $1 \mathrm{~h}$ before sunset (night-day index, NDI). The EOD rate of the time interval $1 \mathrm{~h}$ before sunset was affected in males under AVT treatment (Protocol II, day 3, Figures 3 and 5). Therefore, in these cases, the NDI was calculated taking the representative EOD rate of the time interval $1 \mathrm{~h}$ before sunset from the respective saline control (Protocol II, day 2) after checking that the diurnal EOD rate did not vary from intact fish (Protocol II, day 1) to saline controls (Protocol II, day 2) $(p=0.12$, diurnal EOD rate $_{\text {control }}=8.14(1.7) \mathrm{Hz}$ vs diurnal EOD rate $_{\text {saline }}=9.35(1.8) \mathrm{Hz}$, Wilcoxon Matched-Pairs test, $n=6$ ).

Samples of in vitro electric recordings ( $60 \mathrm{~s}$, taken every $15 \mathrm{~min}$ ) were obtained for up to $120 \mathrm{~min}$ after AVT or MC administration. As in behavioral recordings, the mean interval of each in vitro recording was converted to frequency (firing rate).

Because most data did not follow a normal distribution, they were analyzed using non-parametric statistical tests: Wilcoxon Matched-Pairs test for paired variables in the same fish and MannWhitney $U$ test for independent variables using sets of data from different fish. For the same reason, data are expressed as median and interquartile range (IQR) throughout. All tests used samples of six individuals $(n=6)$.

\section{RESULTS}

\section{EFFECTS OF AVT ON EOD RATE}

We first tested the effects of AVT on EOD rate in Brachyhypopomus gauderio in the simplest resting conditions: freely moving isolated males during daytime in the non-breeding season. As shown in Figure 1A for representative animals, AVT induced an immediate and progressive increase of EOD rate that lasted for at least $120 \mathrm{~min}$ in all tested doses $(n=18)$. AVT did not induce changes in the locomotor activity of fish $\left(p=0.07\right.$, motion $_{\text {preAvT }}$ vs motion postAVT; $_{\text {; }}$;

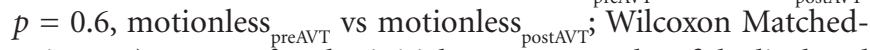
Pairs test). Except for the initial movements that fish displayed when returned to the tank after handling and IP injection, they remained motionless as usually observed during daytime. The amplitude of the EOD rate increase induced by AVT $(1 \mu \mathrm{g} / \mathrm{gbw}$, 60-120 min after injection) was significantly higher than the one induced by saline (Table 1, Figure 1B). Furthermore, this EOD rate increase was higher in fish administered with AVT alone $(1 \mu \mathrm{g} /$ gbw) than in those that received the V1a AVT receptor antagonist (MC, $10 \mu \mathrm{g} / \mathrm{gbw}) 5 \mathrm{~min}$ prior to AVT (Table 1, Figure 1B). The effect of saline and $\mathrm{MC}$ on the amplitude of the EOD rate increase were also significantly different (Table 1, Figure 1B). We observed an important incremental progression in the action of AVT $(1 \mu \mathrm{g} /$ gbw) on EOD rate over time. The EOD rate increase immediately after AVT administration (0-30 min) was significantly lower than the one observed in the last 30 min of the experiment (Table 1, Figure 1D). The blockade the MC exerted on AVT action was also 

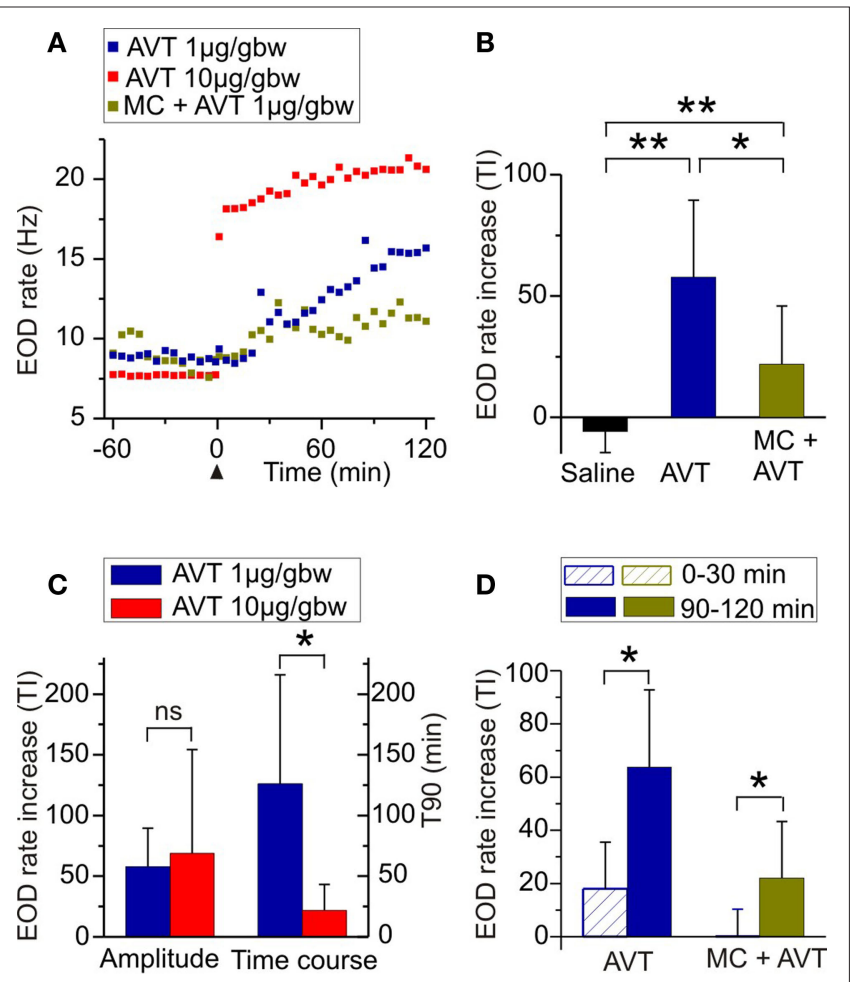

FIGURE 1 | Effects of AVT upon EOD rate in Brachyhypopomus gauderio during the non-breeding season. (A) EOD rate as function of time during daytime in representative individuals of different experimental groups: AVT $(1 \mu \mathrm{g} / \mathrm{gbw})$ in blue; AVT $(10 \mu \mathrm{g} / \mathrm{gbw})$ in red; and MC (AVT antagonist, $10 \mu \mathrm{g} /$ gbw) 5 min prior to AVT $(1 \mu \mathrm{g} / \mathrm{gbw})$ in green. Each treatment was administered at time $=0$ (arrowhead). Each point represents the inverse (frequency) of the mean interval value in $10 \mathrm{~s}$-long samples. (B) Amplitude of the increase of EOD rate induced by AVT $(1 \mu \mathrm{g} / \mathrm{gbw})$ compared to saline controls and to fish that received MC $(10 \mu \mathrm{g} / \mathrm{gbw})+\mathrm{AVT}(1 \mu \mathrm{g} / \mathrm{gbw})$. (C) Dose-response relationship of the effect of AVT ( $1 \mu \mathrm{g} / \mathrm{gbw}$ vs $10 \mu \mathrm{g} / \mathrm{gbw})$ on the amplitude of EOD rate increase and on its time course. (D) Progression of the effects of AVT $(1 \mu \mathrm{g} / \mathrm{gbw})$ and of MC (10 $\mu \mathrm{g} / \mathrm{gbw})+\mathrm{AVT}(1 \mu \mathrm{g} / \mathrm{gbw})$ on the amplitude of EOD rate increase. Bars represent medians (IQR) of treatment indexes ( $\mathrm{TI}$, see Materials and Methods) and of the time it took for the effect to reach $90 \%$ of its maximal value (T90, see Materials and Methods) in (C). ${ }^{*} p<0.05$. ${ }^{*} p<0.01$. (B,C) Mann-Whitney $U$ test. (D) Wilcoxon Matched-Pairs test.

different over time: it completely blocked the effect of AVT $(1 \mu \mathrm{g} /$ gbw) on EOD rate in the first 30 min but only partially prevented the action of AVT during the rest of the recording time (Table 1, Figure 1D). Although the amplitude of the EOD rate increase induced by AVT was not significantly different among AVT doses (Table 1, Figure 1C), the time course of the effect varied with a significant steeper increase of EOD rate at higher doses than lower doses (Table 1, Figure 1C).

Arginine vasotocin at highest dose $(10 \mu \mathrm{g} / \mathrm{gbw})$ affected diurnal EOD rate in isolated B. gauderio but had no effect in G. omarorum as shown in representative individuals of each species in Figures 2A,B, respectively. The EOD rate increase induced by AVT in B. gauderio was higher in the breeding season than in the non-breeding season, but non-significantly different across seasons in amplitude, and showed a similar time course (Table 1). In contrast, AVT only induced transient changes (also observed in saline controls) in the EOD diurnal rate of G. omarorum during both the non-breeding and breeding seasons

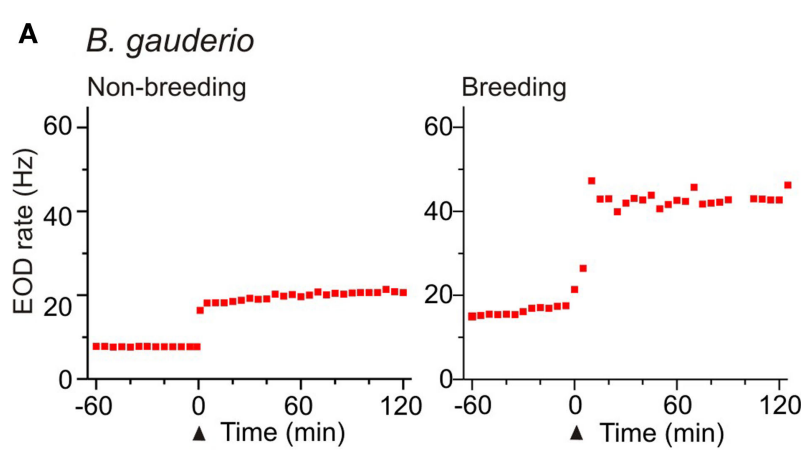

B G. omarorum

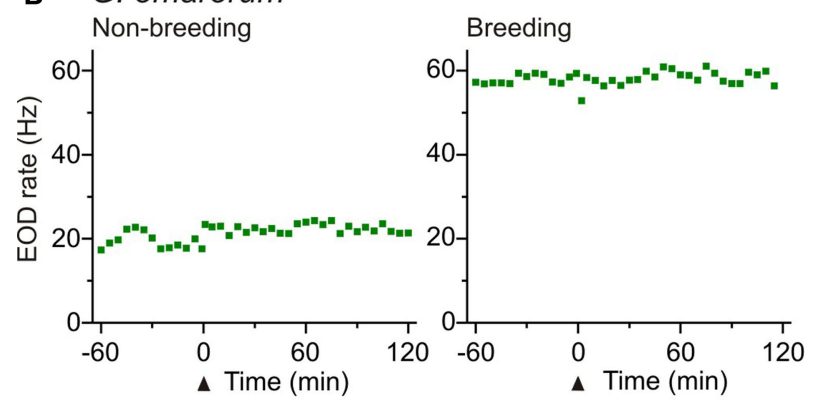

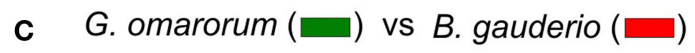

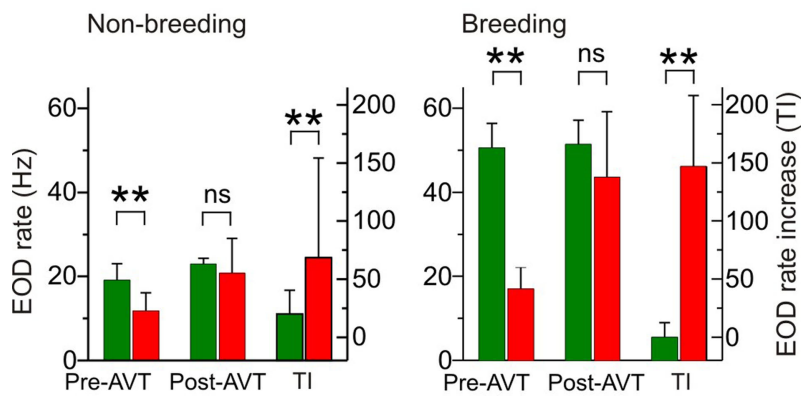

FIGURE 2 | Effects of AVT upon EOD rate in Brachyhypopomus gauderio and Gymnotus omarorum across seasons. (A,B) EOD rate as function of time during daytime in isolated fish during the non-breeding (water temperature: $20-22^{\circ} \mathrm{C}$ ) and breeding (water temperature: $27-29^{\circ} \mathrm{C}$ ) seasons. AVT was administered at time $=0$ (arrowhead). (A) B. gauderio: a long-lasting step-like increase of EOD rate was observed in representative individuals immediately after AVT injection (IP, $10 \mu \mathrm{g} / \mathrm{gbw}$ ) in both the non-breeding and breeding seasons. (B) G. omarorum: no effect of AVT (IP, $10 \mu \mathrm{g} / \mathrm{gbw}$ ) on EOD rate was observed in representative individuals in either the non-breeding or breeding seasons. (C) Left axes: EOD rate of B. gauderio and G. omarorum $1 \mathrm{~h}$ before AVT administration (10 $\mu \mathrm{g} / \mathrm{gbw})$ and 60-120 min after. Right axes: Amplitude of the increase of EOD rate induced by AVT $(10 \mu \mathrm{g} / \mathrm{gbw})$ in both species. Bars represent medians (IQR) of the representative EOD rate values and of treatment indexes (TI, see Materials and Methods). ${ }^{*} p<0.01$, Mann Whitney $U$ test. ns: non-significant.

(Figure 2B). AVT showed no significant effects upon EOD diurnal rate when tested in the entire fish sample during the non-breeding season ( $p=0.056$, Representative EOD rate ${ }_{\text {preAVT }}=19.14$ (3.9) vs Representative EOD rate $_{\text {postAVT }}=22.94$ (1.4), Wilcoxon MatchedPairs test) and the breeding season $(p=0.916$, Representative EOD rate $_{\text {preAVT }}=50.62$ (5.8) vs Representative EOD rate postAVT $=51.43$ (5.7), Wilcoxon Matched-Pairs test). Furthermore, AVT did not induce changes in the locomotor activity of fish $\left(p=0.46\right.$, motion $_{\text {preAvT }}$ vs 
motion $_{\text {postAVT }} ; p=0.06$, motionless preAVT $_{\text {vs motionless }}$ postAVT $_{\text {; Wilcoxon }}$ Matched-Pairs test). On the other hand, the administration of MC $(10 \mu \mathrm{g} / \mathrm{gbw})$ evoked similar changes as saline controls in the diurnal EOD rate of non-breeding isolated G. omarorum in the first $30 \mathrm{~min}$

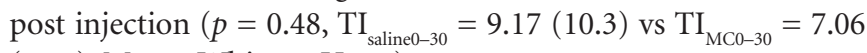
(14.2), Mann-Whitney $U$ test).

As reported elsewhere (Hopkins, 1991; Richer-de-Forges et al., 2009), we observed the characteristic interspecific difference in EOD basal rate that obviously depended on the recording temperature (Figure 2C). The EOD rate of isolated G. omarorum during daytime was significantly higher than the EOD rate of $B$. gauderio before AVT administration in the non-breeding season $\left(p<0.01\right.$, EOD rate $_{\text {Gymn }}=19.14(3.9) \mathrm{Hz}$ vs EOD rate Brac $=11.84$ $(4.3) \mathrm{Hz})$ and in the breeding season $\left(p<0.01\right.$, EOD rate ${ }_{\text {Gymn }}=51.43$ (5.7) $\mathrm{Hz}$ vs EOD rate Brac $=17.06(5) \mathrm{Hz}$ ). Interspecific differences in EOD rate became unapparent after AVT injection $(10 \mu \mathrm{g} / \mathrm{gbw})$ in both seasons as shown in Figure 2C: non-breeding: $p=0.24$, EOD rate $_{\text {Gymn }}=22.94(1.4) \mathrm{Hz}$ vs EOD rate Brac $=20.76(15.6) \mathrm{Hz}$; breeding: $p=0.18$, EOD rate Gymn $=51.43(5.7) \mathrm{Hz}$ vs EOD rate${ }_{\mathrm{Brac}}=43.57(15.6) \mathrm{Hz}$. Consequently, the effect of AVT on EOD rate was different between species; AVT induced an increase in EOD diurnal rate in B. gauderio but not in G. omarorum (non-breeding: $p<0.01, \mathrm{TI}_{\text {Gymn }}=19.94(20.4) \mathrm{Hz}$ vs $\mathrm{TI}_{\text {Brac }}=68.64(85.7) \mathrm{Hz}$; breeding: $p<0.01, \mathrm{TI}_{\text {Gymn }}=-0.06(12.5) \mathrm{Hrac}$ Hz $\mathrm{TI}_{\text {Brac }}=146.83$ (61.1) Hz; Figure 2C).

\section{EFFECTS OF AVT ON THE NOCTURNAL INCREASE OF EOD RATE OF BRACHYHYPOPOMUS GAUDERIO}

The nocturnal increase of EOD rate is a common feature among Gymnotiformes related to their nocturnal habits (Black-Cleworth, 1970; Kawasaki and Heiligenberg, 1989). An additional increase of nocturnal EOD rate has been recently reported in male-female dyads of B. gauderio during breeding, which is modulated by social context and cannot be fully explained by gonadal maturation (Silva et al., 2007). If AVT is responsible for this electric display, it should enhance the nocturnal increase of EOD rate up to breeding values in males in dyadic interactions during the non-breeding season as shown in Figure 3. AVT $(10 \mu \mathrm{g} / \mathrm{gbw})$ injected $65 \mathrm{~min}$ before artificial sunset (to non-breeding males on night 3 of dyadic interactions, Protocol II, day 3) evoked the same abrupt and long-lasting increase in EOD rate already described for isolated males in Figures 1 and 2, and it further increased after sunset (as shown in a representative individual in Figure 3A). The nocturnal increase of EOD rate after AVT administration to non-breeding males was significantly higher than the one in non-injected (data not shown) and saline controls $\left(p<0.05, \mathrm{NDI}_{\text {saline }}=30.05(18.7)\right.$ vs $\mathrm{NDI}_{\text {AVTnon-breeding }}=141.32$ (55.8), Figure 3B) and similar to the one observed in courting males $\left(p=0.06, \mathrm{NDI}_{\mathrm{AVTnon} \text {-breeding }}=141.32(55.8) \mathrm{vs} \mathrm{NDI}_{\text {breeding }}=80.5\right.$ (59.6), Figure 3B).

To test the involvement of AVT in the additional nocturnal increase of EOD rate in B. gauderio, we examined the effect of MC in breeding male-female dyads using a 2-day protocol (Protocol I). As described previously (Silva et al., 2007) and shown in Figure 4A for one representative dyad, the male and the female both exhibited an abrupt and steady increase of their EOD rate during the first night, and males also displayed profuse chirping activity. On night 2 (Figure 4B), this important
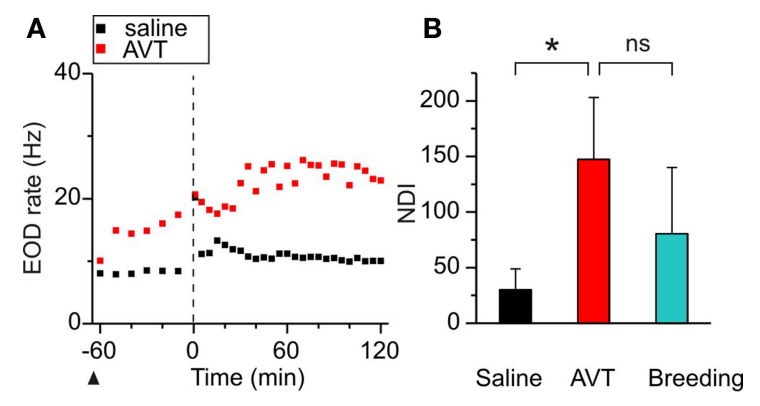

FIGURE 3 | Effects of AVT upon the nocturnal increase of EOD rate in non-breeding Brachyhypopomus gauderio. (A) EOD rate as function of time (60 min before artificial sunset to $120 \mathrm{~min}$ after, lights off at time $=0$, vertical line) in one representative male-female dyad (female data not shown) following Protocol II. Saline was administered to the male 65 min before sunset (arrowhead) and a slight increase of EOD rate was observed during the night (day 2, Protocol II). In day 3, AVT (10 $\mu \mathrm{g} / \mathrm{gbw})$ was administered to the male 65 min before sunset (arrowhead) that evoked an immediate increase of its EOD rate followed by an additional nocturnal increase. (B) Nocturnal EOD rate increase (NDI) of males from different male-female dyads: non-breeding saline controls (Protocol II, day 2), non-breeding males injected with AVT (Protocol II, day 3), and breeding courting males (Protocol II, day 1, breeding). Bars represent medians (IQR) of night-day indexes (NDI, see Materials and Methods).

${ }^{*} p<0.05$, Wilcoxon Matched-Pairs test. Mann-Whitney $U$ test (breeding vs non-breeding). ns: non-significant.

increase of nocturnal EOD rate was still observed in the female. In the male that was injected with $\mathrm{MC}(10 \mu \mathrm{g} / \mathrm{gbw}) 15 \mathrm{~min}$ before artificial sunset, the additional increase of nocturnal EOD rate was significantly prevented $\left(p<0.05, \mathrm{NDI}_{\text {breeding }}=104.49(67.5)\right.$ vs $\mathrm{NDI}_{\text {breeding }+\mathrm{MC}}=56.62(68.8)$, Figure $\left.4 \mathrm{C}\right)$. Interestingly, males continued to emit chirps on night 2.

During the breeding season $B$. gauderio exhibits two different behaviors with distinctive locomotor and electric displays: reproductive behavior and agonistic behavior between males (Perrone et al., 2009). Since AVT is regulator of social behavior that may act differently in different social contexts (Goodson and Kabelik, 2009), we compared the effect of AVT on the nocturnal increase of EOD rate in breeding males in male-female and male-male dyads. The additional increase of nocturnal EOD rate of B. gauderio was also observed in male-male dyads (Figure 5) and it was indistinguishable from the behavior shown in Figure 4A [night 2, Protocol II, $p=0.48, \mathrm{NDI}_{\text {male-female }}=115.22(31.3)$ vs $\mathrm{NDI}_{\text {male-male }}=93.62$ (61.3) ]. Interestingly, AVT injected $65 \mathrm{~min}$ before artificial sunset to breeding males (night 3 of dyadic interactions, Protocol II) induced different effects depending on its social context. The nocturnal increase of EOD rate in males paired with females was significantly higher than the one observed in males paired with other males $\left(p<0.05, \mathrm{NDI}_{\text {male-femaleAVT }}=142.16(49.6) \mathrm{vs} \mathrm{NDI}_{\text {male-maleAVT }}=94.8\right.$ (33.8), Figure 5). In male-female dyads, the chirping activity of the male was not affected by AVT. In male-male dyads, we did not observe conclusive effects of AVT on chirping activity.

\section{EFFECTS OF AVT ON THE FIRING RATE OF THE ISOLATED PACEMAKER NUCLEUS OF BRACHYHYPOPOMUS GAUDERIO}

The spontaneous firing rate of the PN varied among experiments, but it was very stable within each experiment (data not shown). Perfusion of the preparation with AVT $(1 \mu \mathrm{M})$ produced a rapid and 


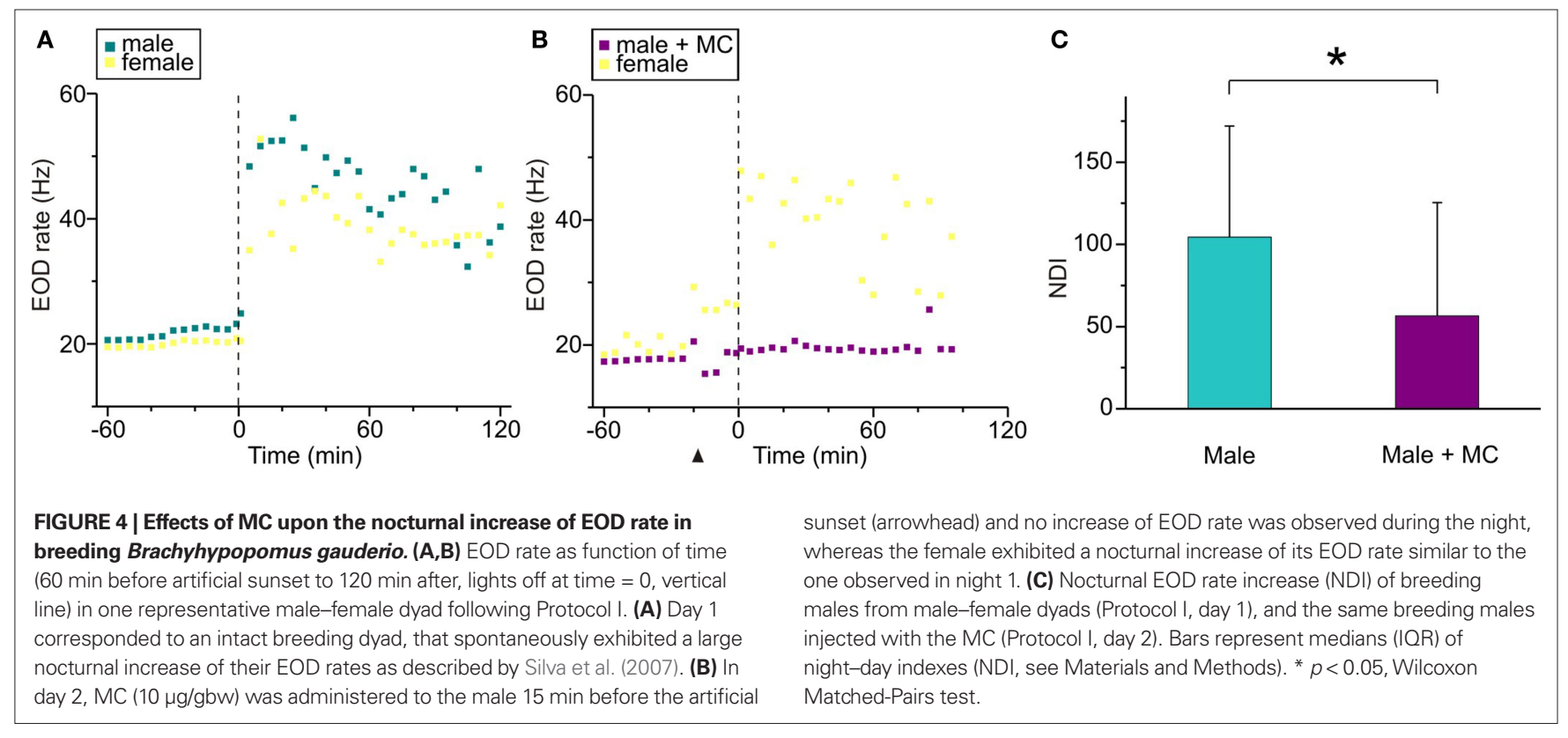

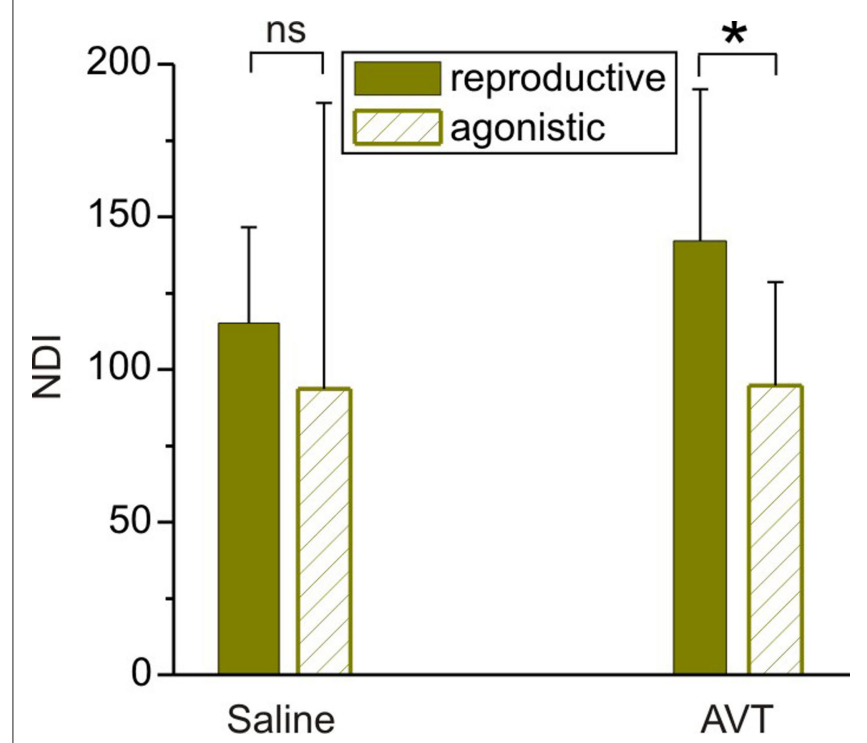

FIGURE 5 | Effects of AVT upon the nocturnal increase of EOD rate in breeding males of Brachyhypopomus gauderio in different social contexts. Nocturnal EOD rate increase (NDI) of breeding males from male-female (reproductive context) and male-male (agonistic context) dyads injected with saline $65 \mathrm{~min}$ before the artificial sunset (Protocol II, day 2), and the same breeding males injected with AVT (Protocol II, day 3, $10 \mu \mathrm{g} / \mathrm{gbw}$, $65 \mathrm{~min}$ before the artificial sunset). Bars represent medians (IQR) of night-day indexes (NDI, see Materials and Methods). ${ }^{*} p<0.05$, Mann-Whitney $U$ test. ns: non-significant.

long-lasting increase in the firing rate of the isolated PN of B. gauderio. There were no significant changes in the waveform of the field potential, thus indicating that the normal sequence of cell activation (pacemaker-relay) was preserved. Figure 6A illustrates representative examples of field potential recordings, obtained in one experiment, showing the basal firing rate (upper trace) and the maximum rate increase following AVT injection (lower trace). The same effects were obtained in the six nuclei tested during the non-breeding season. Figure $\mathbf{6 B}$ presents the temporal course of AVT effect on the PN firing rate. The onset of the AVT effect was already observed $3 \mathrm{~min}$ after its administration and persisted for at least $120 \mathrm{~min}$ after initiating the washout. Maximum increases were obtained about 15-30 min after perfusion. Firing rates measured $15 \mathrm{~min}$ after AVT administration were significantly higher than basal values $(p<0.05$, PN rate $_{\text {preAVT }}=14.8(2.6) \mathrm{Hz}$ vs PN rate postAVT $=27(10) \mathrm{Hz}$, Wilcoxon Matched-Pairs test, Figure $6 \mathrm{C})$. The perfusion of MC $(10 \mu \mathrm{M}, n=4)$ first induced by itself a decrease in the firing rate of the isolated PN. Furthermore, MC initially blocked the effect of AVT when added 30 min later, though the firing rate of the PN partially recovered 60 min after AVT administration (data not shown).

\section{DISCUSSION}

We used a careful behavioral approach framed by the idea that social behavior is regulated by an evolutionarily conserved distributed neural network, and diversity in social behavior is achieved by plasticity in the weighting of activity across the different nodes of the network (Newman, 1999; Goodson, 2005; Goodson and Kabelik, 2009). Our study contributes three main findings: (a) AVT induced an increase of the diurnal EOD rate in Brachyhypopomus gauderio acting directly on the PN; (b) AVT does not affect diurnal EOD rate in Gymnotus omarorum, indicating an interspecific difference in the AVTergic system at the PN level of both species; and (c) AVT is the endogenous modulator of the additional increase of nocturnal EOD rate, relevant electric behavior observed in dyads of B. gauderio during breeding (Silva et al., 2007).

\section{AVT INDUCES AN INCREASE IN THE DIURNAL EOD RATE OF BRACHYHYPOPOMUS GAUDERIO ACTING DIRECTLY ON THE PACEMAKER NUCLEUS}

In a wide variety of vertebrate taxa, exogenous AVT affects social behavior including courtship and aggression in teleost fish (Pickford and Strecker, 1977; Goodson and Bass, 2000a, 2002; Bastian et al., 


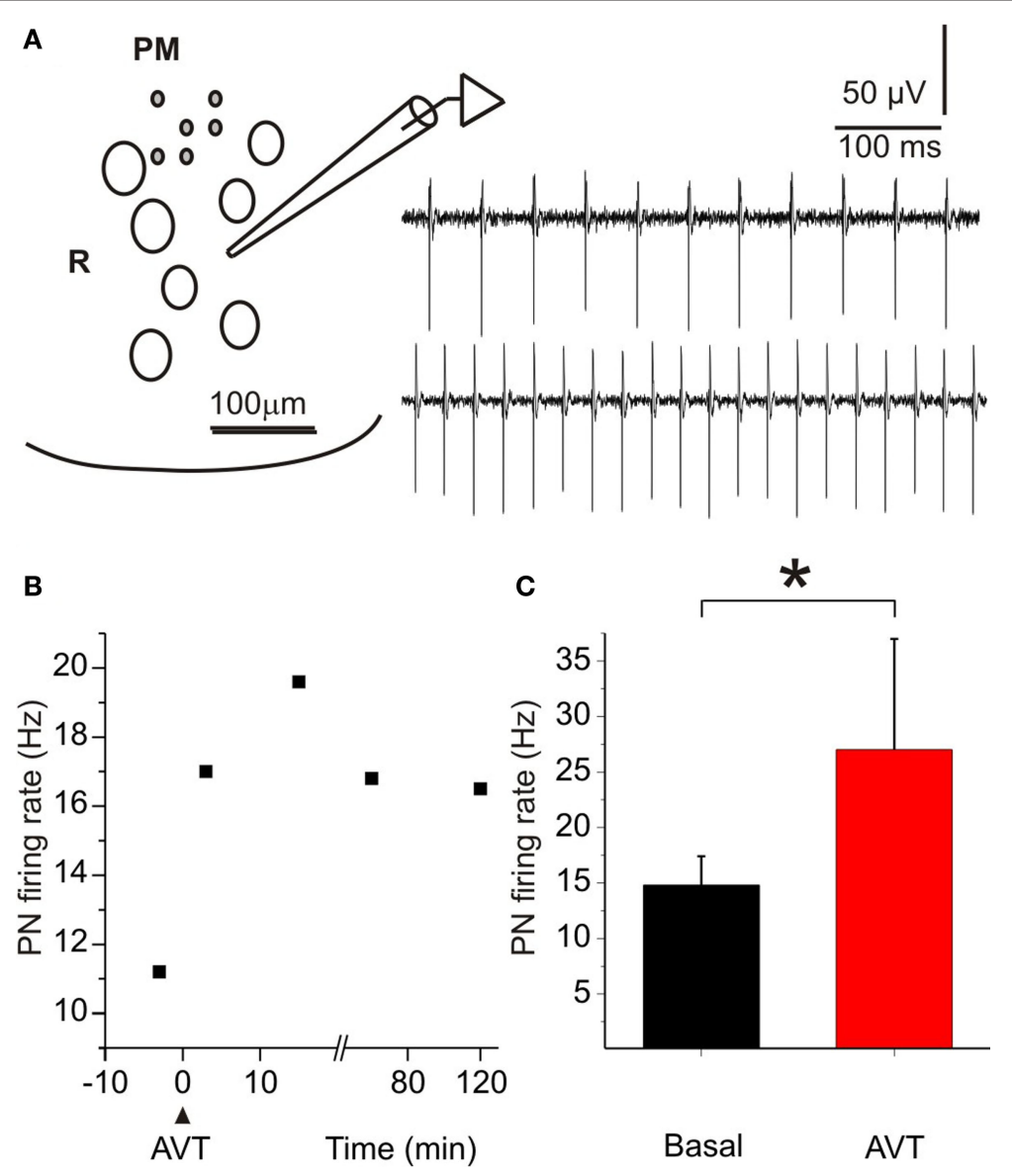

FIGURE 6 | Effects of AVT upon the firing rate of the pacemaker nucleus of Brachyhypopomus gauderio during the non-breeding season. (A) Cartoon of a transverse section of the medulla at the level of the PN (ventral region) to show the position of the recording pipette. PM: pacemaker neurons; R: relay neurons. Field potential recordings in basal conditions (upper trace) and during the maximum effect of AVT (1 $\mu \mathrm{M}$, lower trace). (B) Temporal course of the firing rate increase induced by $A V T$ in one experiment. Maximum effect was observed 15 min after AVT application. (C) PN firing rate before (basal) and 15 min after AVT administration. Bars represent medians (IQR) of PN firing rates. ${ }^{*} p<0.05$, Wilcoxon Matched-Pairs test.
2001; Semsar et al., 2001; Salek et al., 2002; Lema and Nevitt, 2004; Santangelo and Bass, 2006). In many cases, it has been difficult to interpret the underlying mechanisms by which the AVTergic system modulates social behavior given the complexity of behavioral scenarios (multifactorial, with context-dependent and phenotype-dependent actions of AVT). Basal EOD rate modulations encode social information about sex, dominance, and hierarchy (Hagedorn and Heiligenberg, 1985; Lorenzo et al., 2006). Modulation of EOD rate occurs at different time scales. Short-term EOD increases enhance the fish's ability for environmental discrimination (during swimming or novelty responses; Moller, 1995); circadian increases of EOD rate are associated with nocturnal arousal (Black-Cleworth, 1970; Silva et al., 2007); and seasonal and sex-dependent changes in EOD rate are important for reproductive signaling (Hagedorn and Heiligenberg, 1985; Lorenzo et al., 2006). We decided to focus on basal EOD rate because: (a) it is an electric behavior that shows seasonal and social modulation; (b) it is controlled by an unambiguous neural substrate, the EOD rate is set by the spontaneous firing of the pacemaker neurons within the $\mathrm{PN}$; and (c) we can establish controlled experimental conditions to avoid almost all possible interferences.
Arginine vasotocin induced an increase in EOD diurnal rate in isolated B. gauderio across seasons. This effect had an early onset and progressively increased over time up to $120 \mathrm{~min}$ post injection, showing a time course similar to those previously reported on behavioral effects in other teleosts (Semsar et al., 2001; Lema and Nevitt, 2004; Santangelo and Bass, 2006). The dose-response experiment showed no significant dose-dependent effect on the amplitude of the EOD rate increase, probably due to the range of AVT concentrations selected (Santangelo and Bass, 2006). However, it does not seem that we saturated AVT-dependent behaviors, since the time course of the effect (not the duration of the effect but the slope of EOD rate increase, Figure 1C) differed significantly between doses as already reported in teleosts (Goodson and Bass, 2000a). The MC injected prior to AVT prevented its actions both in behavioral and in vitro experiments, suggesting that AVT's modulation of EOD rate is at least in part mediated by V1a AVT receptors. The MC completely blocked AVT effect at first, but AVT actions became evident after 60 min (Figure 1D), suggesting a long-term competence for $\mathrm{V} 1 \mathrm{a}$ receptors. 
Intraperitoneal administration of AVT in teleosts causes systemic increase of AVT levels that promote peripheral as well as central actions depending on AVT doses (Semsar et al., 2001; Lema and Nevitt, 2004). We did not attempt to measure cardiovascular, renal, and osmotic effects of AVT. Central actions of AVT were strongly suggested by behavioral experiments and definitely demonstrated in the in vitro preparation of the PN. Behavioral experiments also suggested that AVT actions on the $\mathrm{PN}$ of B. gauderio were quite specific since AVT did not induce changes in locomotor activity of isolated fish.

The spontaneous firing rate of the pacemaker neurons within the PN determines EOD rate since all the cells involved in the electrogenic pathway fire in a 1:1 fashion (pacemaker neuron-relay bulbospinal neuron-spinal electromotor neuron-peripheral electrocyte; Bennett et al., 1967). The firing rate of the PN can also be modulated by several pre-pacemakers structures lying in the mesencephalon and diencephalon (Spiro et al., 1994). Therefore, the behavioral effects of AVT observed could be mediated by the activation of structures located at different levels of the central nervous system. The main finding of the in vitro experiments is that AVT induces an increase of the firing rate in the isolated PN. This restricted in vitro preparation (which lacks pre-pacemaker structures) can reproduce the rate increase observed in the fish's EOD after AVT injection both in amplitude and time course, indicating that the $\mathrm{PN}$ is a main effector of AVT action. EOD accelerations induced by pre-pacemaker structures through the activation of pacemaker cells (for instance, rate increases in the context of the jamming avoidance response) present two characteristics: the regularity of the discharge rhythm is maintained and the sequence of normal cell activation within the nucleus (pacemaker-relay) is preserved (Kawasaki and Heiligenberg, 1989). Both characteristics are present in the firing rate increases observed in the in vitro preparation after AVT administration, indicating that pacemaker neurons are the target cells of AVT actions. AVT exerts excitatory effects on different types of mammalian central neurons (Raggenbass, 2008). In most cases, this excitation is mediated postsynaptically, by the activation of a non-specific cationic current (usually tetrodotoxin-resistant) and/or by the reduction of a resting potassium conductance. In the case of pacemaker cells that fire spontaneously, there are a large repertoire of membrane currents that are potentially modulated by AVT. Intracellular recordings with voltage clamp would be necessary to clarify AVT mechanisms of action in the pacemaker cells.

The administration of MC induced by itself a decrease in the diurnal EOD rate of isolated fish (data not shown), males in malefemale dyads (Figure 4B), and in the firing rate of the in vitro PN. Opposing effects of AVT and MC on EOD rate strongly suggest the existence of an endogenous basal tone of AVT as observed in other teleosts (Semsar et al., 2001; Santangelo and Bass, 2006). Moreover, the administration of MC prevented the nocturnal increase of EOD rate observed in breeding dyads (Figure 4, see discussion below). We can therefore postulate that endogenous levels of AVT modulate EOD rate in B. gauderio, and that AVT fluctuations across the day-night cycle and across seasons influence the timing, and perhaps also the amplitude, of EOD rate modulations. For example, higher endogenous levels of AVT during breeding would be responsible for the additional increase of nocturnal EOD rate previously reported in this species (Silva et al., 2007). We were unable to demonstrate seasonal differences in the effect of AVT on EOD diurnal rate (Figure 2), most likely because we only used the highest dose $(10 \mu \mathrm{g} / \mathrm{gbw})$ in seasonal experiments. This dose may represent a supraphysiological dose for this species, and therefore unable to discriminate seasonal differences in the sensitivity to AVT. It will be important in the future to examine plasma and/or brain levels of AVT and their fluctuations (that have been reported in other teleosts; Kulczykowska, 1999; Gozdowska and Kulczykowska, 2004) to see how they correlate with daily and seasonal modulations of EOD rate.

\section{INTERSPECIFIC DIFFERENCES IN AVT ACTIONS UPON THE DIURNAL EOD RATE OF BRACHYHYPOPOMUS GAUDERIO AND GYMNOTUS OMARORUM}

Comparisons of closely related species with different social organization have been crucial for understanding the role of AVT as integrator of social behavior (Young et al., 1997; Goodson, 1998a,b; Dewan et al., 2008). Here, we describe an advantageous model system: comparing AVT actions in two species of weakly electric fish with drastically different social organization. G. omarorum occur in solitary locations of the natural habitat (at least $1 \mathrm{~m}$ apart from the closest conspecific), show high sitefidelity, and display intrasexual and intersexual aggression across seasons (Black-Cleworth, 1970). B. gauderio is a gregarious species with intraspecific spacing of about $30 \mathrm{~cm}$, that exhibits an extreme sexual dimorphism suggestive of a polygynous mating system (Hopkins, 1991; Miranda et al., 2008). The only aggression in this species is found between males during the breeding season (Perrone et al., 2009). We focused on the AVT's action on a very simple electric display with well-known neural bases, rather than analyzing its effect on complex multifactorial behaviors. In this way, interspecific differences may be interpreted precisely as locus-specific actions of AVT.

The AVTergic system in teleosts is highly conserved. Cell bodies of AVT neurons lie in the preoptic area of the hypothalamus and project to the pituitary as well as to different regions of the brain. These wide extrahypothalamic projections are the neuroanatomical substrates for the modulation of social behavior by AVT (Van den Dungen et al., 1982; Goodson and Bass, 2000b; Duarte et al., 2001; Saito et al., 2004; Maruska, 2009; Thompson and Walton, 2009). Given that electric fish use their electric discharges as behavioral displays, it is not surprising that AVT projections reach certain components of the electrogenic network. Although the organization of the AVTergic system has not been studied in Gymnotiformes so far, its involvement in the modulation of electric behavior (chirping activity) has been reported in wave-type species (Wong, 2000; Bastian et al., 2001). Our study demonstrates interspecific differences in the AVTergic system between G. omarorum and B. gauderio, probably due to differential organization of AVT projections and/or differential distribution of AVT receptors (Insel and Young, 2000; Goodson, 2008). Behavioral and in vitro experiments indicate the existence of V1a AVT receptors within the PN of B. gauderio that are probably endogenously activated by AVT direct projections. These projections and receptors are apparently missing in the PN of G. omarorum. This evidence encourages us to continue examining the neural substrate of AVT modulation of sociality by tracking the AVTergic system of both species, and exploring the action of AVT in more complex social 
scenarios that involve both the PN and other higher regions of the social brain. Pilot experiments have revealed AVT projections reaching the proximity of the PN in B. gauderio (unpublished data).

Electric organ discharge rate has been traditionally used in the description of Gymnotiformes as a species-specific trait. EOD rate in pulse-Gymnotiformes ranges from 4 to $120 \mathrm{~Hz}$ (Stoddard, 2002). G. omarorum discharges faster than B. gauderio (Figure 2) as previously reported for both species (Hopkins, 1991; Richer-deForges et al., 2009). Within this basal interspecific rate difference, AVT induced a step-like increase in EOD rate in B. gauderio across seasons but had no effect on $G$. omarorum. One could hypothesize that EOD rate differences between species and even the differential effect of AVT upon EOD rate could be attributable to differential endogenous tone of AVT acting on the PN. If G. omarorum were endogenously oversaturated with AVT, it would fire at higher basal rates, and therefore be unaffected by additional AVT. In turn, AVT in B. gauderio (with lower endogenous levels of AVT) would drive its EOD rate up to the maximal possible values, similar to those observed in G. omarorum (Figure 2C). This possibility implies that the PN of pulse-Gymnotiformes would have an AVT-dependent upper limit in its firing rate of around $50 \mathrm{~Hz}$, which is not likely the case. Social interacting B. gauderio exhibit EOD rates above this limit (Perrone et al., 2009). Furthermore, MC by itself did not affect EOD rate in G. omarorum. We therefore believe that AVT is not involved in the regulation of EOD basal rate in this species, at least not in isolated resting animals. AVT might yet affect electric displays in G. omarorum tested in more realistic environmental and social contexts.

Although we focused on a very simple display for the exploration of interspecific differences in the AVT system, we can still speculate that our data may contribute to the understanding of the different social organization of these species. From an adaptive point of view, it is quite interesting that AVT does not affect a communication signal in a solitary and territorial fish. Because G. omarorum interacts very rarely among conspecifics, it may have no need to devote the AVTergic system to modulating electric displays. By contrast, in the gregarious B. gauderio, high levels of social interaction may have selected for the evolution of an AVT social-integrator system coupled to active electroreception. It would be interesting to explore this trend using more pulse-weakly electric fish species with different social structures.

\section{AVT IS THE ENDOGENOUS MODULATOR OF THE SEASONAL ADDITIONAL INCREASE OF NOCTURNAL EOD RATE IN BRACHYHYPOPOMUS GAUDERIO}

The response of EOD rate to AVT treatment in isolated B. gauderio is similar in amplitude and time course to the additional increase of nocturnal EOD rate found only in socially interacting fish during the breeding season (Silva et al., 2007). This prompted us to consider whether AVT was involved in this electric display. The additional increase of nocturnal EOD rate indicates both arousal state and readiness to court, and was understood as a courtship electric signal by itself (Silva et al., 2007). Although it may seem like a non-distinctive display (in contrast to the conspicuous chirps, for example), the nocturnal increase of EOD rate is a meaningful electric social behavior. It has to be interpreted as a risky and energy-costly indicator of male quality in addition to the previously reported waveform sexual dimorphism (Curtis and Stoddard, 2003; Salazar and Stoddard, 2008). The additional increase of nocturnal EOD basal rate exhibits all the requirements to be considered a social behavior: it has seasonal variations, depends on hormone levels, and is modulated by social stimuli. This study demonstrates that AVT is the endogenous agent involved in the additional increase of nocturnal EOD rate of male breeding B. gauderio based on two main findings: (a) it can be mimicked by AVT injections to males in male-female non-breeding dyads that otherwise do not exhibit this electric behavior (Figure 3); and (b) it is blocked in males of breeding male-female dyads when the AVT antagonist (MC) is injected to the male prior to sunset (Figure 4).

The PN, the command organ of EOD basal rate, is also the ultimate effector of transient modulations such as chirps, accelerations, and interruptions (Kawasaki and Heiligenberg, 1989, 1990; Silva et al., 2008). Interestingly, the MC did not inhibit the capacity of chirp emission in breeding males, suggesting an independent regulation of basal and transient modulations of EOD rate, in which only the nocturnal increase of EOD rate might be AVT-dependent. Furthermore, AVT injected to males in male-female dyads affected neither the number nor the type of chirps (data not shown).

The nocturnal increase of EOD rate varies seasonally in B. gauderio (Silva et al., 2007). We did not find seasonal effects of AVT on EOD diurnal rate (Figure 2). Nevertheless, we assume that the AVTergic system in B. gauderio changes accordingly to produce seasonal variations in the nocturnal increase of EOD rate. Previous studies in other teleost fish, have demonstrated seasonal differences in AVT levels or in the number, size, and projections of AVTergic neurons (Ota et al., 1999; Gozdowska and Kulczykowska, 2004; Maruska, 2009). Furthermore, steroid hormones contribute to seasonal variations of AVT expression across vertebrate taxa (Goodson and Bass, 2001). It has been recently demonstrated that the $\mathrm{PN}$ of $B$. gauderio is a target for androgens and that the expression of androgen receptors within the male PN varies seasonally (Pouso, 2009). Therefore, seasonal variations in AVT projections and/or receptors in the $\mathrm{PN}$ of B. gauderio and their steroid dependence should be explored in the future.

Arginine vasotocin modulation of the nocturnal increase of EOD rate in B. gauderio also differs according to social context. Such context-dependent action of AVT appears to be a common feature of social behavior across vertebrates (Trainor et al., 2003; Goodson et al., 2009; Kabelik et al., 2009). Silva et al. (2007) observed the additional increase of nocturnal EOD rate in male-female dyads but not in isolated males. Our present study confirms that male-male dyads exhibit a nocturnal increase of EOD rate similar to the one observed in male-female dyads. Moreover, AVT induced a significantly larger nocturnal increase of EOD rate in males in reproductive context than in those same males in agonistic encounters (Figure 5). This interesting result reinforces the role of the nocturnal increase of EOD rate as a refined social behavior. The signaler courting male is able, via AVT modulation, to enhance this communicative electric display only in the appropriate social context.

\section{CONCLUSIONS}

Social behavior has been shaped by evolutionary forces to produce an extraordinary interspecific, intersexual, and intrasexual diversity. In vertebrates, a complex network of central nuclei (the social brain network; Goodson and Kabelik, 2009), its connections, and distributed plastic patterns of activation account for this diversity. Electric 
fish are traditional neuroethological models mainly because the neural bases of electric behavior can be easily tracked. In particular, the PN offers a direct window through which we can explore inner mechanisms underlying social behavior in close relation to relevant electric behaviors. It commands the rhythm of the EOD and it is also the target organ of steroid hormones and neuropeptides that adaptively adjust rate modulations among seasons, sexes, and social contexts. Although the PN is not a core nucleus of the social brain network but rather a hindbrain effector, it has many advantages for studying the neuromodulation of social behavior. The PN fulfills the

\section{REFERENCES}

Bastian, J., Schniederjan, S., and Nguyenkim, J. (2001). Arginine vasotocin modulates a sexually dimorphic communication behavior in the weakly electric fish Apteronotus leptorhynchus. J. Exp. Biol. 204, 1909-1923.

Bennett, M. V. L., Pappas, G. D., Gimenez, M., and Nakajima, Y. (1967). Physiology and ultrastructure of electrotonic junctions. IV. Medullary electromotor nuclei in gymnotid fish. J. Neurophysiol. 30, 236-300.

Black-Cleworth, P. (1970). The role of electrical discharges in the non-reproductive social behavior of Gymnotus carapo (Gymnotidae, Pisces). Anim. Behav. 3, 1-77.

Caputi, A.A., Carlson, B. A., and Macadar, O. (2005). "Electric organs and their control," in Electroreception, eds T. H. Bullock, C. D. Hopkins, A. N. Popper, and R. R. Fay (New York: Springer), 410-451.

Curtis, C. C., and Stoddard, P. K. (2003). Mate preference in female electric fish, Brachyhypopomus pinnicaudatus. Anim. Behav. 66, 329-336.

De Vries, G. J., and Panzica, G. C. (2006). Sexual differentiation of central vasopressin and vasotocin systems in vertebrates: different mechanisms, similar endpoints. Neuroscience 138, 947-955.

Dewan, A. K., Maruska, K. P., and Tricas, T. C. (2008). Arginine vasotocin neuronal phenotypes among congeneric territorial and shoaling reef butterflyfishes: species, sex and reproductive season comparisons. J. Neuroendocrinol. 20, 1382-1394.

Duarte, G., Segura-Noguera, M. M., Martín del Río, M. P., and Mancera, J. M. (2001). The hypothalamohypophyseal system of the white seabream Diplodus sargus: Immunocytochemical identification of arginine-vasotocin, isotocin, melanin-concentrating hormone and corticotropin-releasing factor. Histochem. J. 33, 569-578.

Falconi, A., Lorenzo, D., Curti, S., Morales, F. R., and Borde, M. (1997). Mauthner cell-evoked synaptic actions on pace- maker medullary neurons of a weakly electric fish. J. Comp. Physiol. A 181, 143-151.

Giora, J., and Malabarba, L. R. (2009). Brachyhypopomus gauderio, new species, a new example of underestimated species diversity of electric fishes in the southern South America (Gymnotiformes: Hypopomidae). Zootaxa 2093, 60-68.

Goodson, J. L. (1998a). Territorial aggression and dawn song are modulated by septal vasotocin and vasoactive intestinal polypeptide in male field sparrows (Spizella pusilia). Horm. Behav. 34, 67-77.

Goodson, J. L. (1998b). Vasotocin and vasoactive intestinal polypeptide modulate aggression in a territorial songbird, the violet-eared waxbill (Estrildidae: Uraeginthus granatina) Gen. Comp. Endocrinol. $111,233-244$.

Goodson, J. L. (2005). The vertebrate social behavior network: evolutionary themes and variations. Horm. Behav. $48,11-22$.

Goodson, J. L. (2008). Nonapeptides and the evolutionary patterning of sociality. Prog. Brain Res. 170, 3-15.

Goodson, J. L., and Bass, A. H. (2000a). Forebrain peptides modulate sexually polymorphic vocal circuitry. Nature 403, 769-772.

Goodson, J. L., and Bass, A. H. (2000b). Vasotocin innervation and modulation of vocal-acoustic circuitry in the teleost Porichthys notatus. J. Comp.

Goodson, J. L., and Bass, A. H. (2001). Social behavior functions and related anatomical characteristics of vasotocin/vasopressin systems in vertebrates. Brain Res. Rev. 35, 246-265.

Goodson, J. L., and Bass, A. H. (2002). Vocal-acoustic circuitry and descending vocal pathways in teleost fish: Convergence with terrestrial vertebrates reveals conserved traits. J. Comp. Neurol. 448, 298-322.

Goodson, J. L., and Kabelik, D. (2009). Dynamic limbic networks and social diversity in vertebrates: from neural context to neuromodulatory patNeurol. 422, 363-379.

requirements of any component of the social brain network with the benefits of being quite independent and experimentally accessible, thus allowing us to dissect out essential mechanisms of the neural bases of sociality from the complexity of the social brain.

\section{ACKNOWLEDGMENTS}

We wish to thank Kent Dunlap, Sat Gavassa, and Laura Quintana for their generous revision and suggestions to our manuscript. This research was supported by ANII, project FCE2007_569, and PEDECIBA.

terning. Front. Neuroendocrinol. 30, 429-441.

Goodson, J. L., Schrock, S. E., and Kabelik, D. (2009). Dynamic neuromodulation of aggression by vasotocin: Influence of social context and social phenotype. Biol. Lett. 5, 554-556.

Gozdowska, M., and Kulczykowska, E. (2004). Determination of argininevasotocin and isotocin in fish plasma with solid-phase extraction and fluorescence derivatization followed by high-performance liquid chromatography. J. Chromatogr. B Analyt. Technol. Biomed. Life Sci. 807, 229-233.

Hagedorn,M., and Heiligenberg, W.(1985). Court and spark: electric signals in the courtship and mating of gimnotoid fish. Anim. Behav. 33, 254-265.

Hopkins, C. D. (1991). Hypopomus pinnicaudatus (Hypopomidae), a new species of gymnotiform fish from French Guiana. Copeia 1, 151-161.

Insel, T. R., and Young, L. J. (2000). Neuropeptides and the evolution of social behavior. Curr. Opin. Neurobiol. 10, 784-789.

Kabelik, D., Klatt, J. D., Kingsbury, M. A., and Goodson, J.L. (2009). Endogenous vasotocin exerts context-dependent behavioral effects in a semi-naturalistic colony environment. Horm. Behav. 56 101-107.

Kawasaki, M., and Heiligenberg, W. (1989). Distinct mechanisms of modulation in a neuronal oscillator generate different social signals in the electric fish Hypopomus. J. Comp. Physiol. A 165, 731-741.

Kawasaki, M., and Heiligenberg, W. (1990). Different classes of glutamate receptors and GABA mediate distinct modulations of a neuronal oscillator, the medullary pacemaker of a gymnotiform electric fish. J. Neurosci. 10 , 3896-3904.

Keller, C. H., Kawasaki, M., and Heiligenberg, W. (1991). The control of pacemaker modulations for social communication in the weakly electric fish Sternopygus. J. Comp. Physiol. A. 169, 441-450.

Kulczykowska, E. (1999). Diel changes in plasma arginine vasotocin, isotocin, and melatonin in rainbow trout (Oncorhynchus mykiss). Fish Physiol. Biochem. 21, 141-146.

Lema, S. C., and Nevitt, G. A. (2004). Exogenous vasotocin alters aggression during agonistic exchanges in male Amargosa River pupfish (Cyprinodon nevadensis amargosae). Horm. Behav. 46, 628-637.

Lissmann, H. (1958). On the function and evolution of electric organs in fish. $J$. Exp. Biol. 35, 156-191.

Lorenzo, D., Silva, A., and Macadar, O. (2006). "Electrocommunication in Gymnotiformes: jamming avoidance and social signals during courtship," in Communication in Fishes, Vol 2., eds B. G. Kapoor, F. Ladich, S. P. Collin, and P. Moller (Enfield, NH: Science Publishers), 753-779.

Maruska, K. P. (2009). Sex and temporal variations of the vasotocin neuronal system in the damselfish brain. Gen. Comp. Endocrinol. 160, 194-204.

Miranda, M., Silva, A. C., and Stoddard, P. K. (2008). Use of space as an indicator of social behavior and breeding systems in the gymnotiform electric fish Brachyhypopomus pinnicaudatus. Environ. Biol. Fishes 83, 379-389.

Moller, P. (1995). "Active electrolocation," in Electric Fishes. History and Behavior Fish and Fisheries Series 17, ed. P. Moller (London: Chapman and Hall), 111-132.

Newman, S. W. (1999). The medial extended amygdala in male reproductive behavior. A node in the mammalian social behavior network. Ann. N. Y. Acad. Sci. 877, 242-257.

Ota, Y., Ando, H., Ueda, H., and Urano, A. (1999). Seasonal changes in expression of neurohypophysial hormone genes in the preoptic nucleus of immature female masu salmon. Gen. Comp. Endocrinol. 116, 31-39.

Perrone, R., Macadar, O., and Silva, A. (2009). Social electric signals in freely moving dyads of Brachyhypopomus pinnicaudatus. J. Comp. Physiol. A 195, 501-514.

Pickford, G. E., and Strecker, E. L. (1977). The spawning reflex response of the 
killifish, Fundulus heteroclitus: isotocin is relatively inactive in comparison with arginine vasotocin. Gen. Comp. Endocrinol. 2, 132-137.

Pouso, P. (2009). Exploración de variaciones estacionales a nivel del Núcleo Electromotor Bulbar de Brachyhypopomus pinnicaudatus. Tesis de Maestría en Ciencias Biológicas. Universidad de la Republica, PEDECIBA.

Raggenbass, M. (2008). Overview of cellular electrophysiological actions of vasopressin. Eur. J. Pharmacol. 583, 243-254.

Richer-de-Forges, M. M., Crampton, W. G. R., and Albert, J. S. (2009). A new species of Gymnotus (Gymnotiformes, Gymnotidae) from Uruguay: Description of a model species in neurophysiological research. Copeia 3, 538-544.

Saito, D., Komatsuda, M., and Urano, A. (2004). Functional organization of preoptic vasotocin and isotocin neurons in the brain of rainbow trout: central and neurohypophysial projections of single neurons. Neuroscience 124, 973-984.

Salazar, V., and Stoddard, P. K. (2008). Sex differences in energetic costs explain sexual dimorphism in the circadian rhythm modulation of the electrocommunication signal of the gymnotiform fish Brachyhypopomus pinnicaudatus. J. Exp. Biol. 211, 1012-1020.

Salek, S. J., Sullivan, C. V., and Godwin, J. (2002). Arginine vasotocin effects on courtship behavior in male white perch (Morone americana). Behav. Brain Res. 133, 177-183.

Santangelo, N., and Bass, A. H. (2006). New insights into neuropeptide modulation of aggression: field studies of arginine vasotocin in a territorial tropical damselfish.Proc. Biol. Sci. 273, 3085-3092.

Semsar, K., Kandel, F. L. M., and Godwin, J. (2001). Manipulations of the AVT system shift social status and related courtship and aggressive behavior in the bluehead wrasse. Horm. Behav. 40, 21-31.

Silva, A., Perrone, R., and Macadar, O. (2007). Environmental, seasonal, and social modulations of basal activity in a weakly electric fish. Physiol. Behav. 90, 525-536.

Silva, A., Quintana, L., Galeano, M., and Errandonea, P. (2003). Biogeography and breeding in Gymnotiformes from Uruguay. Environ. Biol. Fishes 66, 329-338.

Silva, A., Quintana, L., Perrone, R., and Sierra, F. (2008). Sexual and seasonal plasticity in the emission of social electric signals. Behavioral approach and neural bases. J. Physiol. (Paris). 102, 272-278.

Spiro, J. E., Brose, N., Heinemann, S. F., and Heiligenberg, W. (1994). Immunolocalization of NMDA receptors in the central nervous system of weakly electric fish: functional implications for the modulation of a neuronal oscillator. J. Neurosci. 10, 6289-6299.

Stoddard, P. K. (2002). Electric signals: Predation, sex, and environmental constraints. Adv. Study Behav. 31, 201-242.

Thompson, R., and Walton, J. C. (2009). Vasotocin immunoreactivity in goldfish brains: characterizing primitive circuits associated with social regulation. Brain Behav. Evol. 73,153-164.

Trainor, B. C., Rouse, K. L., and Marler, C. A. (2003). Arginine vasotocin interacts with the social environment to regulate advertisement calling in the gray treefrog (Hyla versicolor). Brain Behav. Evol. 61,165-171.

Van den Dungen, H. M., Buijs, R. M., Pool,C.W., and Terlou, M. (1982). The distribution of vasotocin and isotocin in the brain of the rainbow trout. J. Comp. Neurol. 212,146-167.

Wong, C. J. H. (2000). Electrical stimulation of the preoptic area in Eigenmannia evoked interruptions in the electric organ discharge. J. Comp. Physiol. A. 186, 81-93.
Young, L. J. (2009). The neuroendocrinology of the social brain. Front. Neuroendocrinol. 30, 425-428.

Young, L. J., Winslow, J. T., Nilsen, R., and Insel, T. R. (1997). Species differences in V1a receptor gene expression in monogamous and nonmonogamous voles: Behavioral consequences. Behav. Neurosci. 111, 599-605.

Conflict of Interest Statement: The authors declare that the research was conducted in the absence of any commercial or financial relationships that could be construed as a potential conflict of interest.

Received: 28 February 2010; paper pending published: 29 June 2010; accepted: 16 July 2010; published online: 13 August 2010.

Citation: Perrone R, Batista G, Lorenzo D, Macadar O and Silva A (2010) Vasotocin actions on electric behavior: interspecific, seasonal, and social context-dependent differences. Front. Behav. Neurosci. 4:52. doi: 10.3389/fnbeh.2010.00052

Copyright (c) 2010 Perrone, Batista, Lorenzo, Macadar and Silva. This is an open-access article subject to an exclusive license agreement between the authors and the Frontiers Research Foundation, which permits unrestricted use, distribution, and reproduction in any medium, provided the original authors and source are credited. 